\title{
Cyclophilin A Plays Potential Roles in a Rat Model of Asthma and Suppression of Immune Response
}

\author{
Cai-Tao Chen (ID) \\ Chun-Xiao Shan ${ }^{2}$ \\ Jun $\operatorname{Ran}^{3}$ \\ Lei-Miao Yin' \\ Hai-Yan $\mathrm{Li}^{4}$ \\ Yu Wang (D)' \\ Yu-Dong Xu (D) \\ Jing-Lei Guo ${ }^{5}$ \\ Yang-Lin Shi ${ }^{1}$ \\ Yan-Jiao Chen (D)' \\ Yong-Qing Yang'
}

'Shanghai Research Institute of Acupuncture and Meridian, Yueyang Hospital of Integrated Traditional

Chinese and Western Medicine, Shanghai University of Traditional Chinese

Medicine, Shanghai, People's Republic of

China; ${ }^{2}$ Changchun University of Chinese

Medicine, Changchun, Jilin, People's

Republic of China; ${ }^{3}$ Chongqing Hospital

of Traditional Chinese Medicine,

Chongqing, People's Republic of China;

${ }^{4}$ Shanghai First Rehabilitation Hospital,

Shanghai, People's Republic of China;

${ }^{5}$ School of Basic Medical Sciences,

Shanghai University of Traditional

Chinese Medicine, Shanghai, People's

Republic of China

\begin{abstract}
Purpose: Cyclophilin A (CypA) inhibits $\mathrm{CD}^{+} \mathrm{T}$ cell signal transduction via interleukin2-inducible T-cell kinase (Itk), a tyrosine kinase required for T helper (Th) 2 cells function. Furthermore, mice with CypA silencing developed allergic diseases associated with increased Th2 cytokines production. $\mathrm{CD} 4^{+} \mathrm{T}$ cells with a Th2-cytokine pattern have been demonstrated to have a pivotal role in the pathogenesis of asthma. However, the effects of CypA in regulating immunity in asthma and in relieving asthmatic symptoms in vivo are entirely unknown.
\end{abstract}

Methods: Recombinant CypA protein ( $\mathrm{rCypA})$ was generated and purified. Ovalbumin (OVA)-challenged asthmatic rats model and acetylcholine chloride (ACh)-induced contraction of tracheal spirals were established. The pulmonary resistance (RL) value of asthmatic rats in vivo and the isometric tension of tracheal spirals ex vivo were recorded by MFLab 3.01 software. The levels of Th1 and Th2 cytokines and the quantities of immunoglobulin (IgA, IgG, IgM and IgE) in the supernatants of rat spleen lymphocytes were detected and analysed by bio-plex Suspension Array System and ELISA, respectively. CD4 ${ }^{+} \mathrm{T}$ cells were separated by MicroBeads, and the levels of interleukin (IL)- 4 and interferon- $\gamma$ (IFN- $\gamma$ ) were detected by ELISA.

Results: $\mathrm{rCypA}(10 \mathrm{ng} / \mathrm{kg}$ ) significantly reduced RL within 2-7 min in OVA-challenged asthmatic rats in vivo, and there were no significant differences compared with terbutaline (TB) and hydrocortisone (HC). Furthermore, rCypA $(10 \mathrm{ng} / \mathrm{mL})$ significantly reduced the isometric tension in the $\mathrm{ACh}$-induced contraction of the tracheal spiral ex vivo, and the effect of rCypA was better than that of TB. Additionally, rCypA suppressed the secretion of both Th1 and Th2 cytokines, and the suppressive effects of rCypA were stronger than those of $\mathrm{HC}$, especially on Th2 cytokines.

Conclusion: These findings indicate that CypA may serve as a potential novel therapeutic strategy for asthma.

Keywords: cyclophilin A, asthma, Th2 cytokines, immunoregulation

\section{Introduction}

Asthma is a disease that characterized by airway inflammation and manifests as reversible airway obstruction. ${ }^{1}$ It now affects 300 million individuals and accounts for 1 in every 250 deaths worldwide. ${ }^{2,3}$ The preferred treatment for asthma is the combination of inhaled corticosteroids (ICS) and long-acting $\beta_{2}$ agonist (LABA) in clinics, ${ }^{1}$ even though the side effects of ICS and LABA in asthmatic patients have been recognized for decades. ${ }^{4,5}$ Other options such as leukotriene receptor antagonists, azithromycin, or anti-immunoglobulin E monoclonal antibodies are used in patients whose asthma is not well controlled by ICS-LABA therapy. ${ }^{6-8}$ However,
Correspondence: Yong-Qing Yang; Yan-jiao Chen

Laboratory of Molecular Biology, Shanghai Research Institute of Acupuncture and Meridian, Shanghai University of

Traditional Chinese Medicine, 650 South Wanping Road, Shanghai, 200030,

People's Republic of China

$\mathrm{Tel}+86-2$ I-54592। 34; +86-2I-64395975

Fax+86-2I-64395975

Email yyq@shutcm.edu.cn;

cyjbl018@I63.com 
despite receiving optimal therapy, there is still a group of asthmatic patients who continue to have symptoms, in particular, associated with the $\mathrm{T}$ helper (Th) 2 immune response including interleukin (IL)-4 and IL-13. ${ }^{9}$ Therefore, there is an urgent need for new drugs and targets for asthma, especially inhibitors of the Th2 immune response. ${ }^{10}$

Corticosteroids are the first-line therapy against asthma in the clinic and have immunosuppressive effects. ${ }^{11,12}$ Immunosuppressive agents for asthma have been concerned since then, such as purine antagonists, methotrexate and cyclosporin $\mathrm{A}(\mathrm{CsA}){ }^{13} \mathrm{CsA}$ is a powerful immunosuppressive agent that was used against asthma by inhibiting the production of cytokines, predominantly in those produced by $\mathrm{T}$ lymphocytes. ${ }^{14} \mathrm{CsA}$ is an effective treatment in severe corticosteroid-dependent asthma and significantly improves pulmonary function in the clinic. ${ }^{15}$ Despite the potential benefits of CsA for asthma, the toxic effects of elevated liver enzymes, hypertrichosis, neuropathy/paraesthesia, and gastrointestinal disturbances have been established. ${ }^{16}$ Nonetheless, CsA mediates its immunosuppressive effects by combining with the peptidyl prolyl isomerase (PPIase) of the Cyclophilin $\mathrm{A}(\mathrm{CypA}),{ }^{17}$ and CypA is the primary mediator of immunosuppression by CsA. ${ }^{18}$ This suggests that CypA may contribute to immunosuppressive effects by inhibiting the activity of $\mathrm{T}$ cells in asthma.

CypA is a ubiquitous protein with PPIase, it was the first identified and is the most abundantly expressed member of the family of Cyclophilins. ${ }^{19}$ Generally, CypA is presented intracellularly (iCypA), and it can be secreted from cells (called extracellular CypA, eCypA) in response to inflammatory stimuli such as hypoxia, infection, and oxidative stress. $^{20-22}$ In addition to the immunosuppressive function of CypA bound to CsA, a previous study also revealed that $\mathrm{CypA}$ catalysed the isomerization of the T cell-specific Tec family member interleukin-2-inducible T-cell kinase (Itk). CypA promotes the dimerization of Itk, decreases the activity of Itk protein-kinase activity, and inhibits intracellular signalling events, thereby inhibiting

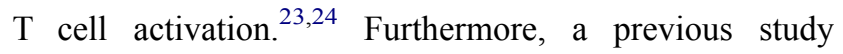
showed that CypA/Ppia ${ }^{-/}$mice developed allergic diseases with elevated immunoglobulin (Ig) E and Th2 cytokines (particularly IL-4), ${ }^{25}$ probably reflecting the essential role of CypA in regulating immunity in allergic diseases, including asthma, and its potential role in relieving asthmatic symptoms.
In the study, recombinant CypA protein ( $\mathrm{rCypA}$ ) was generated and purified, and the effects of rCypA in both ovalbumin (OVA)-challenged asthmatic rats in vivo and acetylcholine chloride (ACh)-induced contraction of tracheal spirals ex vivo were clarified. Furthermore, the effect of rCypA on the cytokine profile of lymphocytes, particularly the regulation of $\mathrm{Th} 1 / \mathrm{Th} 2$ cytokines balance, was studied.

\section{Materials and Methods Purification of Recombinant CypA}

The recombinant human pET21a-CypA plasmid was donated by Dr. Xu Shen (Shanghai Institute of Materia Medica, Chinese Academy of Sciences). ${ }^{26}$ The plasmid was transfected into E. coli BL21 (DE3) strain (Merck Millipore, USA). In the protein expression procedure, 0.1 $\mathrm{mM}$ isopropyl-beta-D-thiogalactopyranoside (IPTG) (Beyotime Biotechnology Co. Ltd., China) was added when the optical density at $600 \mathrm{~nm}$ reached 0.6 , and protein expression was induced at $37^{\circ} \mathrm{C}$ for 12 h. E. coli cells were harvested and resuspended in resuspension buffer (20 mM PB, $300 \mathrm{mM} \mathrm{NaCl}, \mathrm{pH} \mathrm{7.4)}$ and then broken by ultrasonication on ice. After that, Triton X-100 (Beyotime Biotechnology Co. Ltd., China) was added, and the supernatant was collected. rCypA was purified in 2 steps. The first step was affinity chromatography purification using $\mathrm{Ni}^{+}$Sepharose 6 Fast Flow beads (Danaher Corporation Life Sciences platform, USA), and the second step was ion-exchange chromatography purification using Q Sepharose Fast Flow beads (Danaher Corporation Life Sciences platform, USA). The purity of rCypA was confirmed by SDS-PAGE with purity higher than 95\% (Supplementary Figure S1A). In addition, the PPIase activity of rCypA was measured by the method described previously. ${ }^{27}$ With the addition of $\alpha$ chymotrypsin, the rate of reaction significantly improved, implying the obvious PPIase activity of rCypA (Supplementary Figure S1B).

\section{Preparation of Ovalbumin-Challenged Asthmatic Rats Model}

Sprague Dawley (SD) rats $(120 \pm 10$ g) were used and purchased from the Shanghai Experimental Animal Centre (SLAC Laboratory Animal Co. Ltd., China) in the study. All rats were housed in specific-pathogen free (SPF) conditions with a temperature of $20-22^{\circ} \mathrm{C}$ and air humidity of $45-55 \%$ on a regular light-dark schedule. 
Rats were randomly divided into 5 groups with 8 rats in each group. The groups were the control group (Blank); asthmatic rats group (AS); asthmatic rats with $0.055 \mathrm{mg} /$ kg terbutaline (Chengdu Huayu Pharmaceutical Co. Ltd., China) group (TB); asthmatic rats with $15.0 \mathrm{mg} / \mathrm{kg}$ hydrocortisone (Tianjin Biochem Pharmaceutical Co. Ltd., China) group (HC); and asthmatic rats with $10.0 \mathrm{ng} / \mathrm{kg}$ rCypA group (rCypA). TB and $\mathrm{HC}$, two drugs widely used to control asthma symptoms in the clinic, were used as positive controls. The dose of two drugs was prepared according to the previous work. ${ }^{28}$

The rats in the AS, TB, HC and rCypA groups were sensitized and challenged with OVA (Sigma-Aldrich Co. Ltd., USA) as previously described. ${ }^{28}$ On day 0 , rats were intraperitoneally injected with $1 \mathrm{mg}$ of OVA precipitated with $10 \mathrm{mg}$ of $\mathrm{Al}(\mathrm{OH})_{3}$ gel (Shanghai AiBi Chemical Reagent Co. Ltd., China) dissolved in $1 \mathrm{~mL}$ of normal saline (NS) $(0.9 \% \mathrm{NaCl})$. On day 14 , the rats were injected with $0.055 \mathrm{mg} / \mathrm{kg} \mathrm{TB}, 15.0 \mathrm{mg} / \mathrm{kg} \mathrm{HC}$ and $10 \mathrm{ng} / \mathrm{kg} \mathrm{rCypA}$ through the external jugular vein $10 \mathrm{~min}$ prior to challenge with OVA ( $5 \mathrm{mg} / \mathrm{kg}$ body weight), respectively. Rats in the Blank group were sensitized and challenged with NS only.

\section{Measurement of Pulmonary Resistance}

The rats were placed on a fixed plate in a supine position, kept warm by incandescent bulb after anesthetized. Expose the trachea and made a T-shaped incision at the upper part of the trachea. Meanwhile, gently inserted a T-shaped cannula into the trachea, which was directly connected with a heater-controlled pneumotachograph (Hans Rudolf Inc., USA). The flow rate and tidal volume were measured by connecting the heater-controlled pneumotachograph with a differential pressure transducer (Kent Scientific Corporation, USA). Another cannula was inserted into the esophagus to the mid-thorax level, and connected to a physiological pressure transducer (Shanghai Jialong Instrument Factory, China) to detect the transpulmonary pressure. Pulmonary resistance (RL) was calculated over a complete respiratory cycle using an integrated method, in which flows, volumes, and pressures were continuously recorded by MFLab 3.01 software (Shanghai Medical College, Fudan University, China), as described previously. $^{28}$

\section{Preparation of Rat Tracheal Spirals}

Preparation of rat tracheal spirals was conducted according to the previously described protocol. ${ }^{28}$ Briefly, the rats were anaesthetized, and then the trachea was taken out and cut into a 3-5 mm width and $15-18 \mathrm{~mm}$ length spiral. The lower part of the tracheal spiral was fixed to a support in the tissue bath, and the upper part was connected to the tension transducer (Shanghai Jialong Instrument Factory, China), prepared for experimental procedures described below.

\section{Measurement of Isometric Tension}

The optimal concentration of ACh (Sigma-Aldrich Co. Ltd., USA) was $1 \times 10^{-5} \mathrm{~g} / \mathrm{mL}$, and the normal contraction degree of the tracheal spiral ex vivo was $70 \%(0.51 \pm 0.09$ g). The study of the measurement of isometric tension was divided into 5 groups: normal tracheal spiral group (Blank); tracheal spiral pre-treated with $10 \mu \mathrm{g} / \mathrm{mL} \mathrm{ACh}$ group (ACh); tracheal spiral pre-treated with $10 \mu \mathrm{g} / \mathrm{mL}$ ACh and $0.015 \mathrm{mg} / \mathrm{mL}$ of TB group (TB); tracheal spiral pre-treated with $10 \mu \mathrm{g} / \mathrm{mL}$ ACh and $9 \mathrm{mg} / \mathrm{mL}$ of $\mathrm{HC}$ group (HC); and tracheal spiral pre-treated with $10 \mu \mathrm{g} / \mathrm{mL} \mathrm{ACh}$ and $10 \mathrm{ng} / \mathrm{mL}$ rCypA group (rCypA). The dose of $\mathrm{ACh}$, $\mathrm{TB}$ and $\mathrm{HC}$ were prepared according to the previous work. ${ }^{28,29}$ The isometric tension value of tracheal spirals was continuously monitored for 10 min with MFLab 3.01 (Shanghai Medical College, Fudan University, China) software, and the data obtained from each group were summarized and analysed.

\section{Cell Cultures}

Lymphocytes were isolated from the spleens of normal SPF SD rats, and the proportion of lymphocytes was analysed by flow cytometry. $\mathrm{T}$ lymphocytes were labelled with FITC anti-rat CD3 (BD Biosciences, USA), accounting for $24.60 \pm 1.61 \%$. B lymphocytes were labelled with PE anti-rat CD45RA (BD Biosciences, USA), accounting for $48.71 \pm 3.22 \%$.

In addition, $\mathrm{CD}^{+} \mathrm{T}$ cells were separated by rat $\mathrm{CD} 4$ MicroBeads (Miltenyi Biotec, Germany) for subsequent experiments. The purity of $\mathrm{CD}^{+}{ }^{+} \mathrm{T}$ cells was determined by flow cytometry, and the purity of the isolated $\mathrm{CD} 4{ }^{+}$ $\mathrm{T}$ cells in the study was more than $95 \%$ (Supplementary Figure S2A and B). All cells $\left(5 \times 10^{5}\right.$ cells $\left./ \mathrm{mL}\right)$ were cultured in a 24-well plate in RPMI-1640 medium (Gibco/life Technologies, USA) containing 10\% FBS (Gibco/life Technologies, USA) and $100 \mathrm{U} / \mathrm{mL}$ penicillin- $100 \mu \mathrm{g} / \mathrm{mL}$ streptomycin (Gibco/life Technologies, USA) solution.

The lymphocytes isolated from spleens were divided equally into 2 parts: the control part and the experimental part. In the control part, all cells were suspended and cultured with RPMI-1640 medium (Non-stimulated, Non-stim), 
and based on that 4 groups were set. They were the RPMI-1640 medium only group (baseline); rCypA $(0.0032,0.016,0.08,0.4$ and $2 \mu \mathrm{g} / \mathrm{mL})$ groups; ${ }^{30}$ positive control drug $\mathrm{HC}(0.2 \mathrm{mg} / \mathrm{mL})$ group $^{31}$ and negative control protein bovine serum albumin (BSA) $(0.4 \mu \mathrm{g} / \mathrm{mL})$ group. In the experimental part, cells were suspended and cultured with RPMI-1640 medium and $5 \mu \mathrm{g} / \mathrm{mL}$ pokeweed mitogen (PWM) (Gibco/life Technologies, USA), namely, the PWMstimulated group (PWM-stim). Based on that, 4 groups were set according to the control part. Cells in each group were cultured for 5 days and incubated in a humidified incubator at $37^{\circ} \mathrm{C}$ with $5 \% \mathrm{CO}_{2}$. After that, the supernatants were collected and used for further analysis.

The isolated $\mathrm{CD}^{+} \mathrm{T}$ cells were divided equally into 5 groups, cells cultured with RPMI-1640 medium (Blank); cells cultured with $5 \mu \mathrm{g} / \mathrm{mL}$ Concanavalin A (Con A) (Sigma-Aldrich Co. Ltd., USA) group; cells cultured with $5 \mu \mathrm{g} / \mathrm{mL}$ Con A and $0.2 \mathrm{mg} / \mathrm{mL} \mathrm{HC}$ group (HC); cells cultured with rCypA $(0.001,0.01,0.1,0.2$ and $0.5 \mu \mathrm{g} / \mathrm{mL})$ groups (rCypA); and cells cultured with $5 \mu \mathrm{g} / \mathrm{mL}$ Con A and $0.4 \mu \mathrm{g} / \mathrm{mL}$ BSA group (BSA). Cells in each group were cultured for 4 days and incubated in a humidified incubator at $37^{\circ} \mathrm{C}$ with $5 \% \mathrm{CO}_{2}$. After that, the supernatants were collected and used for further analysis.

\section{Cytokine Multiplex Assay}

The cytokines in supernatants from the isolated splenic lymphocytes were measured by Suspension Array System (Bio-Rad Laboratories, Inc. USA) using a Bio-Plex Pro Rat cytokine multiplex assay kit (Bio-Rad Laboratories, Inc. USA). Cytokines, including Th1 cytokine IL-2, interferon$\gamma($ IFN- $\gamma)$, Th2 cytokine IL-4, IL-5, IL-10, IL-13 and tumour necrosis factor alpha (TNF- $\alpha$ ) were analysed. The assay was performed according to the manufacturer's instructions.

\section{ELISA}

The quantities of immunoglobulin (IgA, IgG, $\operatorname{IgM}$ and $\operatorname{IgE}$ ) in supernatants from the isolated lymphocytes of spleens and cytokines (IL-4, IFN- $\gamma$ ) in supernatants from isolated CD4 ${ }^{+}$ T cells were measured by ELISA kits (R\&D Systems, USA).

\section{Statistical Analysis}

All experimental data are presented as the mean $\pm \mathrm{SEM}$. Comparisons among groups were performed using oneway ANOVA. Differences between two groups were analysed by Bonferroni's post hoc test. A $P$-value of less than 0.05 was considered statistically significant.

\section{Results}

\section{Recombinant CypA Reduces RL in Ovalbumin-Challenged Asthmatic Rats}

The data in the study showed that the RL in the AS group increased significantly within 2-8 min after OVA challenge $(P<0.05$ versus Blank, Figure 1A). These results confirm the positive early allergen-specific airway response of asthmatic rats to OVA. The RL in both the $\mathrm{TB}$ and $\mathrm{HC}$ groups decreased significantly during the $2-8$ min period of the early airway response $(P<0.05$ versus $\mathrm{AS}$, Figure 1A). This indicates that both of the positive drugs TB and $\mathrm{HC}$ have a significant reduction effect on $\mathrm{RL}$ in asthmatic rats, which was consistent with the clinical effect. Furthermore, the data showed that rCypA (10 ng/ $\mathrm{kg})$ significantly reduced the RL within $2-7 \mathrm{~min}(P<0.05$ versus the AS group, Figure 1A). The effects of rCypA on the sum value in RL during the 2-4 min of the early airway response showed no significant differences compared with the positive drugs $\mathrm{TB}$ and $\mathrm{HC}$ (Figure 1B). This indicates that $10 \mathrm{ng} / \mathrm{kg}$ CypA has almost the same effect in reducing the RL in the rat model of asthma with $0.055 \mathrm{mg} / \mathrm{kg} \mathrm{TB}$ and $15 \mathrm{mg} / \mathrm{kg} \mathrm{HC}$.

\section{Recombinant CypA Reduces ACh-Induced Isometric Tension of Tracheal Spirals}

ACh significantly increased the isometric tension from the beginning 1 to $10 \mathrm{~min}(P<0.05$ versus blank, Figure $2 \mathrm{~A})$ in the study. The positive drugs $\mathrm{HC}$ and TB completely abrogated the ACh-induced isometric tension at $1-10 \mathrm{~min}(P<$ 0.05 versus ACh, Figure 2A). The data showed that rCypA $(10 \mathrm{ng} / \mathrm{mL})$ significantly reduced isometric tension, and the effect lasted for at least $10 \mathrm{~min}(P<0.05$ versus $\mathrm{ACh}$, Figure 2A), indicating that $\mathrm{rCypA}$ inhibits contraction effects on tracheal spirals. Similarly, the data in Figure 2B showed that the sum value of isometric tension of $\mathrm{rCypA}(10$ $\mathrm{ng} / \mathrm{mL}$ ) from 1 to $10 \mathrm{~min}$ significantly decreased the AChinduced isometric tension of the tracheal spiral. Notably, the inhibitory effect of $10 \mathrm{ng} / \mathrm{mL}$ rCypA is almost 1.6-fold more efficient than that of $0.015 \mathrm{mg} / \mathrm{mL} \mathrm{TB}$.

\section{Suppressive Effects of Recombinant CypA on Cytokines and Immunoglobulins}

The current study reveals that the imbalance of Th1/Th2 cytokines contributes to the aetiology and pathogenesis of asthma. $^{32}$ In this study, PWM was used to stimulate the 
A

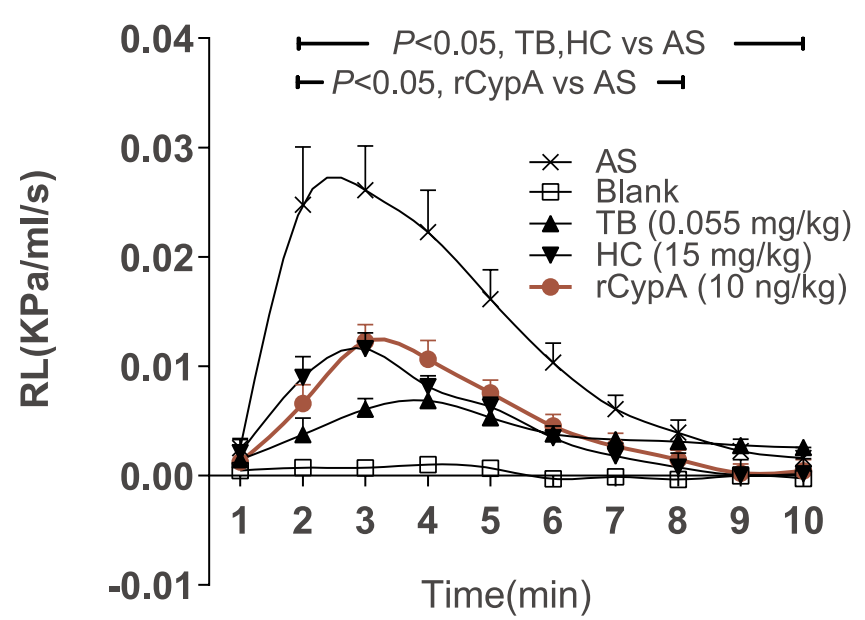

B

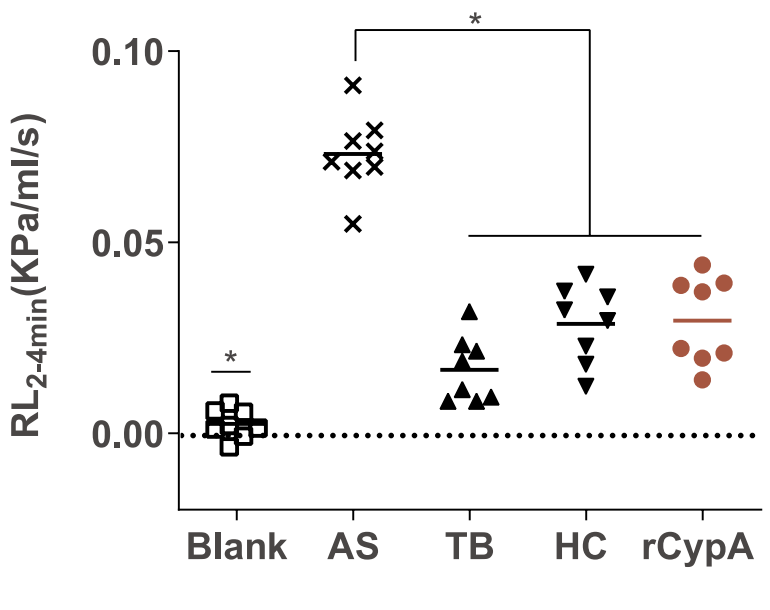

Figure I Effects of rCypA on pulmonary resistance (RL) in asthmatic rats. (A) Time-response curves of blank, asthmatic rats (AS), terbutaline (TB), hydrocortisone (HC) and recombinant CypA $(\mathrm{rCypA})$ in asthmatic rats. The data are presented as the mean \pm SEM $(n=8)$. (B) Boxplot analysis of the sum value in $R L$ during the $2-4$ min of the early airway response $\left(\mathrm{RL}_{2-4 \mathrm{~min}}\right)$ * $* P<0.05$ for $\mathrm{TB}, \mathrm{HC}$ and $\mathrm{rCypA}$ groups vs $\mathrm{AS}$ group.

A

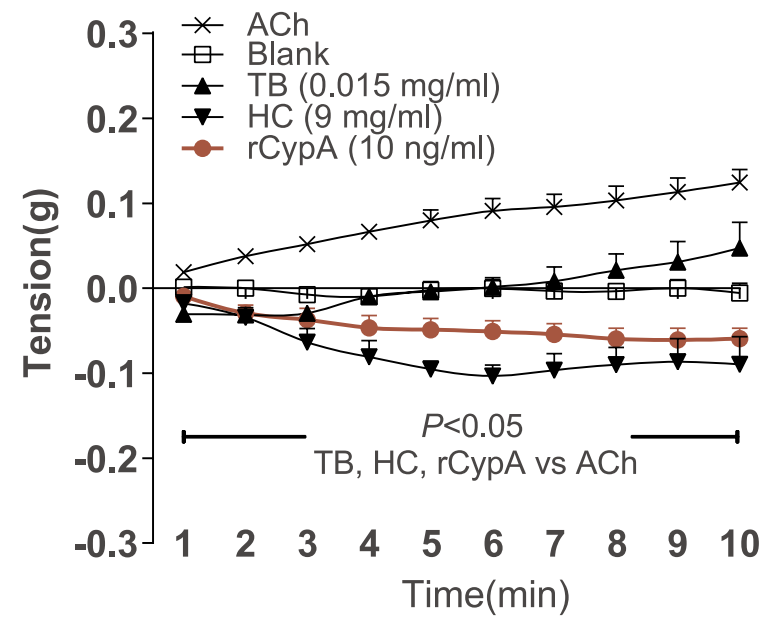

B

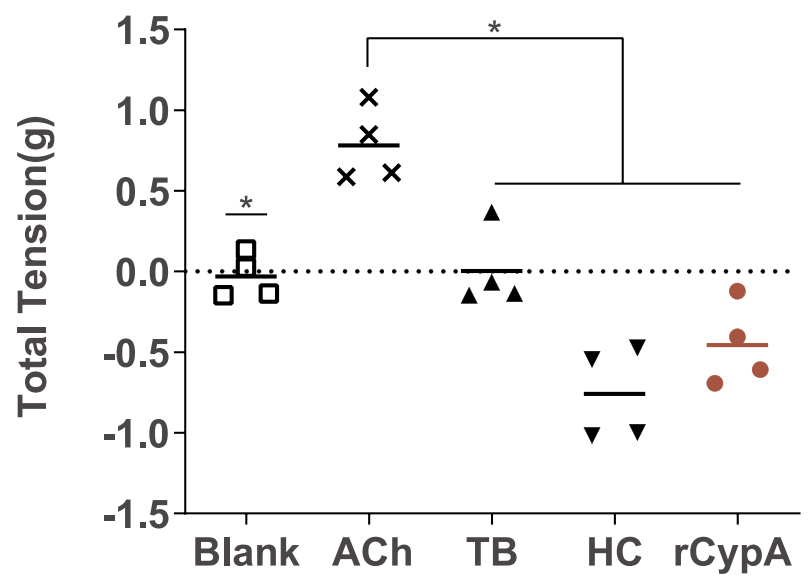

Figure 2 Effects of rCypA on isometric tension of tracheal spirals. (A) Time-response curves of the blank, ACh group (ACh), terbutaline (TB), hydrocortisone (HC) and recombination CypA ( $\mathrm{rCypA}$ ) groups in isolated tracheal spirals. The data are presented as the mean \pm SEM $(n=4)$. (B) Boxplot analysis of the sum of isometric tension among all the groups. ${ }^{*} P<0.05$ for $\mathrm{TB}, \mathrm{HC}$ and $\mathrm{rCypA}$ groups vs $\mathrm{ACh}$ group.

proliferation and differentiation of both $\mathrm{B}$ and T lymphocytes in the PWM-stim group. The Non-stim group was set to represent the normal physiological state of cells as a control. Different doses of rCypA were added and the effect of $\mathrm{rCypA}$ in regulating Th1/Th2 cytokines balance was observed in both the Non-stim and PWM-stim groups in vitro.

In the PWM-stim group, the data showed that PWM promoted the secretion of IL-2, IFN- $\gamma$, IL-4, IL-10, IL-13 and TNF- $\alpha(P<0.05)$ but not IL-5 $(P>0.05)$, and none of these cytokines were significantly changed in the Non-stim group ( $P>0.05$, Figure 3$)$. HC, a type of glucocorticoid, inhibited the levels of IL-2, IFN- $\gamma$, IL-4, IL-10, IL-13, TNF- $\alpha$ and IL-5 $(P<0.05$, Figure 3$)$ in both the Nonstim and PWM-stim groups. As a negative control, BSA only influenced the levels of IL-2, IL-4 and IL-13 in the PWM-stim group (Figure 3).

Significant inhibitory effects on Th1 cytokines (represented by IL-2 and IFN- $\gamma$ ) were observed under rCypA concentrations of $0.0032,0.016,0.08,0.4$ and $2 \mu \mathrm{g} / \mathrm{mL}(P<0.05$, respectively, Figure 3) in the PWM-stim group, and the inhibitory effects were dose-dependent. Meanwhile, 

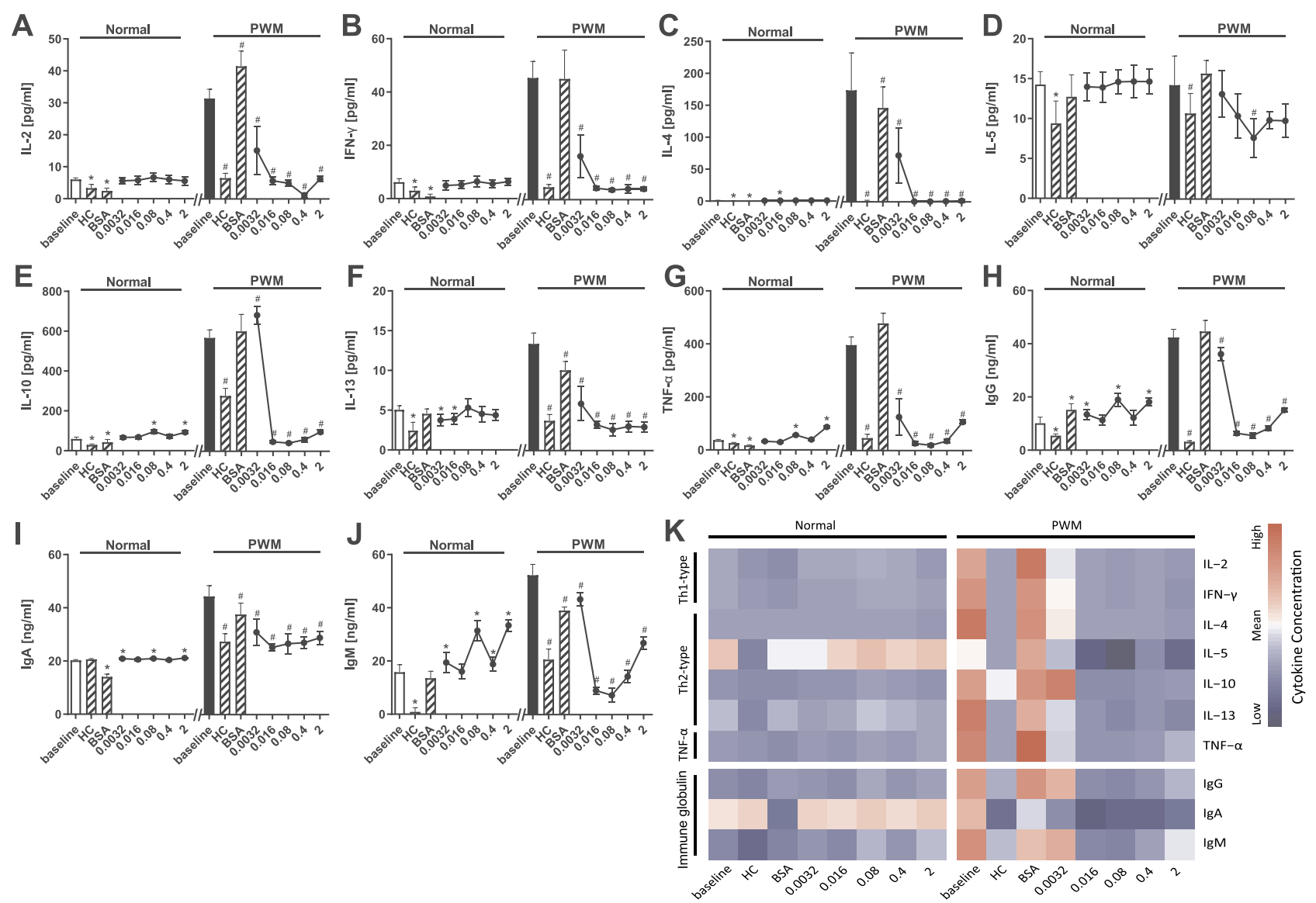

Figure 3 Suppression effects of recombinant CypA on cytokines and immunoglobulins. (A-J) The concentrations of cytokines and immunoglobulins. The unit of each cytokine is described as $\mathrm{pg} / \mathrm{mL}$. The unit of each immunoglobulin is described as $\mathrm{ng} / \mathrm{mL}$. Data are presented as the mean $\pm \mathrm{SEM}$ ( $\mathrm{n}=8$ ). $* P<0.05 \mathrm{vs}$ baseline in the Nonstim group; ${ }^{\#} P<0.05$ vs baseline in the PWM-stim group. (K) Heatmap of the cytokines profile for Th1, Th2, TNF- $\alpha$ and immunoglobulin in supernatants of lymphocytes.

significant inhibitory effects on Th2 cytokines (represented by IL-4, IL-10 and IL-13) were observed under rCypA at $0.0032-2 \mu \mathrm{g} / \mathrm{mL}$, and the inhibitory effects of rCypA on Th2 cytokines were also in a dose-dependent manner, similar to those exerted on Th1 cytokines. Changes in the levels of most Th1 cytokines and Th2 cytokines were not observed under rCypA at different concentrations in the Non-stim group $(P>$ 0.05 , Figure 3). Furthermore, the level of TNF- $\alpha$ was inhibited under rCypA at $0.0032-2 \mu \mathrm{g} / \mathrm{mL}$ in the PWM-stim group, but displayed an elevated trend in the Non-stim group under the same concentration of rCypA (Figure 3).

The data showed that the levels of immunoglobulins, including IgG, IgA and IgM were suppressed by rCypA at $0.0032-2 \mu \mathrm{g} / \mathrm{mL}$ in the PWM-stim group, but slightly promoted in the Non-stim group at the same concentration of rCypA. Additionally, the level of IgE was not detected in either the Non-stim or PWM-stim groups, which is consistent with a previous report showing that $\operatorname{IgE}$ is generally more difficult to detect because of its low frequency in the spleen (Figure 3). ${ }^{33}$

\section{Effects of Recombinant CypA on IL-4 and IFN- $\gamma$ Levels in Separated CD4 ${ }^{+}$T Cells}

To determine the effect of CypA on Th2 cytokines (IL-4) and Th1 cytokines (IFN- $\gamma$ ), Con A was used to stimulate T cells, and the levels of IL-4 and IFN- $\gamma$ were measured. The data showed that Con A significantly promoted the secretion of IL4 and IFN- $\gamma(P>0.05)$, and the positive drug HC significantly inhibited the level of IL-4 $(P>0.05)$. Significant inhibitory effects on IL-4 levels were observed for rCypA $(0.01,0.1,0.2$ and $0.5 \mu \mathrm{g} / \mathrm{mL}$ ), and the inhibitory effects of rCypA were dose-dependent $(P<0.05$, respectively, Figure 4A). However, the IFN- $\gamma$ level was only inhibited under rCypA at the dose of $0.2 \mu \mathrm{g} / \mathrm{mL}$ (Figure 4B). As a negative control, BSA had no influence on the levels of IL-4 and IFN- $\gamma$. 

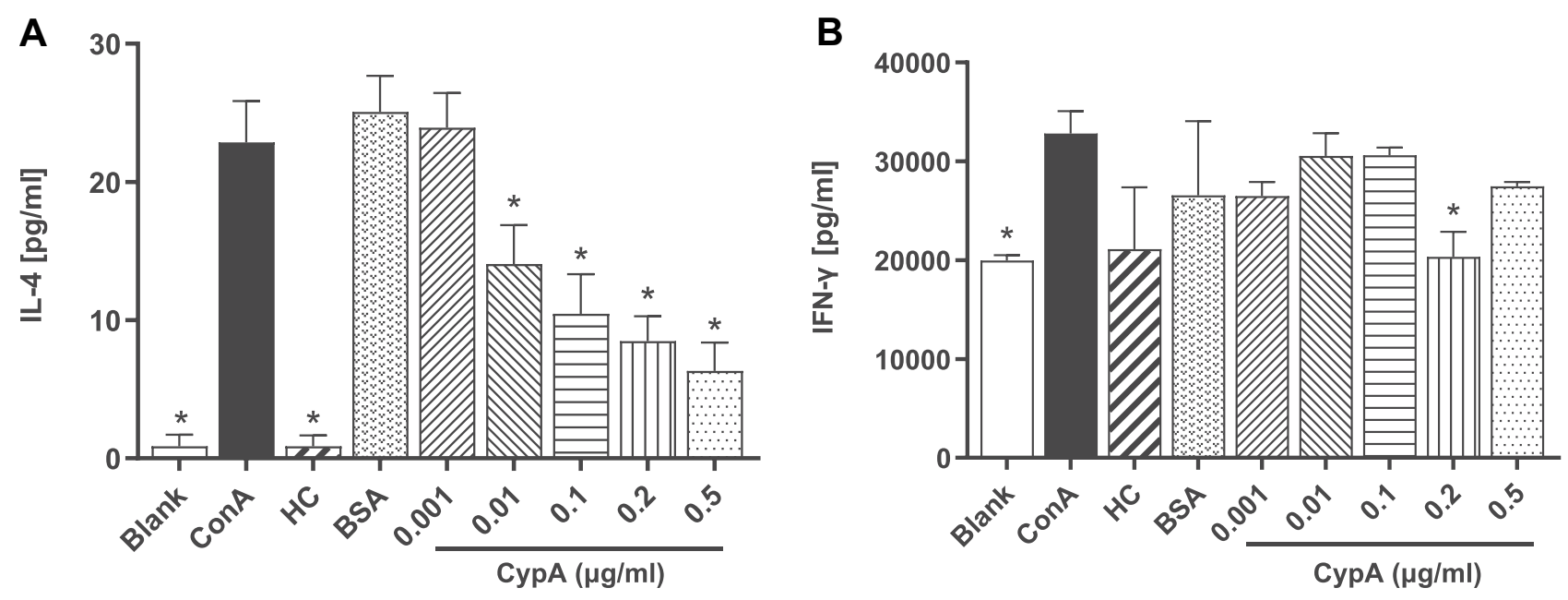

Figure 4 Effects of recombinant CypA on IL-4 and IFN- $\gamma$ levels in separated CD4 ${ }^{+}$T cells. (A) The concentrations of IL-4 in different groups. (B) The concentrations of IFN$\gamma$ in different groups. The unit of each cytokine is described as $\mathrm{Pg} / \mathrm{mL}$. Data are presented as the mean $\pm \operatorname{SEM}(n=4)$. *P< $<.05$, when compared with the Con A group.

\section{Discussion}

The hallmark features of asthma involve airway inflammation, and variable airflow obstruction. Inflammation in asthma consists of airway infiltration by lymphocytes, mast cells, and eosinophils. ${ }^{34}$ There is accumulating evidence that $\mathrm{CD}^{+}$lymphocytes with a Th2-cytokine pattern play a pivotal role in the aetiology and pathogenesis of asthma.

A previous study reported that mice with CypA silencing developed an allergic condition associated with increased Th2 cytokines production; meanwhile, CypA was able to inhibit the activity of $\mathrm{T}$ cells by repressing Itk activity. Thus, to identify the effects of CypA in regulating immunity in asthma, PWM and Con A were used to produce the Th2 polarization effect similar to that of asthma in vitro.

PWM can stimulate the proliferation and differentiation of both B and T lymphocytes. The data in this study showed that when rCypA was added to the PWM-stim group, a significant suppressive effect was shown on both Th1 and Th2 cytokines. The suppressive effect of rCypA reported in this study was similar but not quite the same as with the effect of $\mathrm{HC}$, which is a well-known immunosuppressive agent. ${ }^{35}$ Both rCypA and HC played an inhibitory role in the secretion of Th1 and Th2 cytokines, while the suppressive effects of rCypA were stronger than those of $\mathrm{HC}$, especially on Th2 cytokines (Figure 5). In addition, rCypA showed a greater advantage in the modulation of Th1 and Th2 cytokines than $\mathrm{HC}$ in this study. The ratio of Th1/Th2 cytokines was not altered in the $\mathrm{HC}$ group, whereas in the rCypA group, the ratio of Th1/Th2 cytokines returned to normal proportions (Figure 5). Another aspect of rCypA should be noted is that the inhibitory effect of rCypA on Th1 and Th2 cytokines was only observed in PWM-stim group but not in the Non-stim group, while HC showed significant inhibitory effects in both the Non-stim and PWM-stim groups. The results of this study confirm the immunosuppressive effects of rCypA in inhibiting the cytokines production of $\mathrm{T}$ cells and balancing Th1 and Th2 cytokines. Furthermore, among all of these cytokines, a less suppressive effect of rCypA was only observed for IL-5. We tried to determine the fundamental reasons and mechanisms underlying this observation. Finally, we noticed that there was a narrow range of IL-5 production under the stimulation of $\mathrm{PWM},{ }^{36}$ which is in accordance with our data in Figure 3D. To further clarify the role of rCypA on T cells, Con A was used. Consistent with the suppressive effect of rCypA under PWM, significant inhibitory effects on IL-4 levels were found.

On the other hand, the effects of rCypA in vivo and ex vivo were studied. These data showed that rCypA significantly reduced the RL after the rats were challenged. However, the expression of eCypA has been reported to be persisted upregulated in the bronchoalveolar lavage fluid of both acute and chronic asthmatic mice. ${ }^{37}$ In addition, in the case of eCypA present in nasal wash samples collected from asthma patients in the chronic phase of asthma, levels of CypA are undetectable in many samples. ${ }^{38,39}$ In the previous study conducted by our team, down-regulated expression of rCypA mRNA was found in the lung tissues of an asthmatic rat model (data not published). Therefore, the inconsistency between the present study and others likely resulted from differences in phase detection techniques, animal species and measurement locations. 


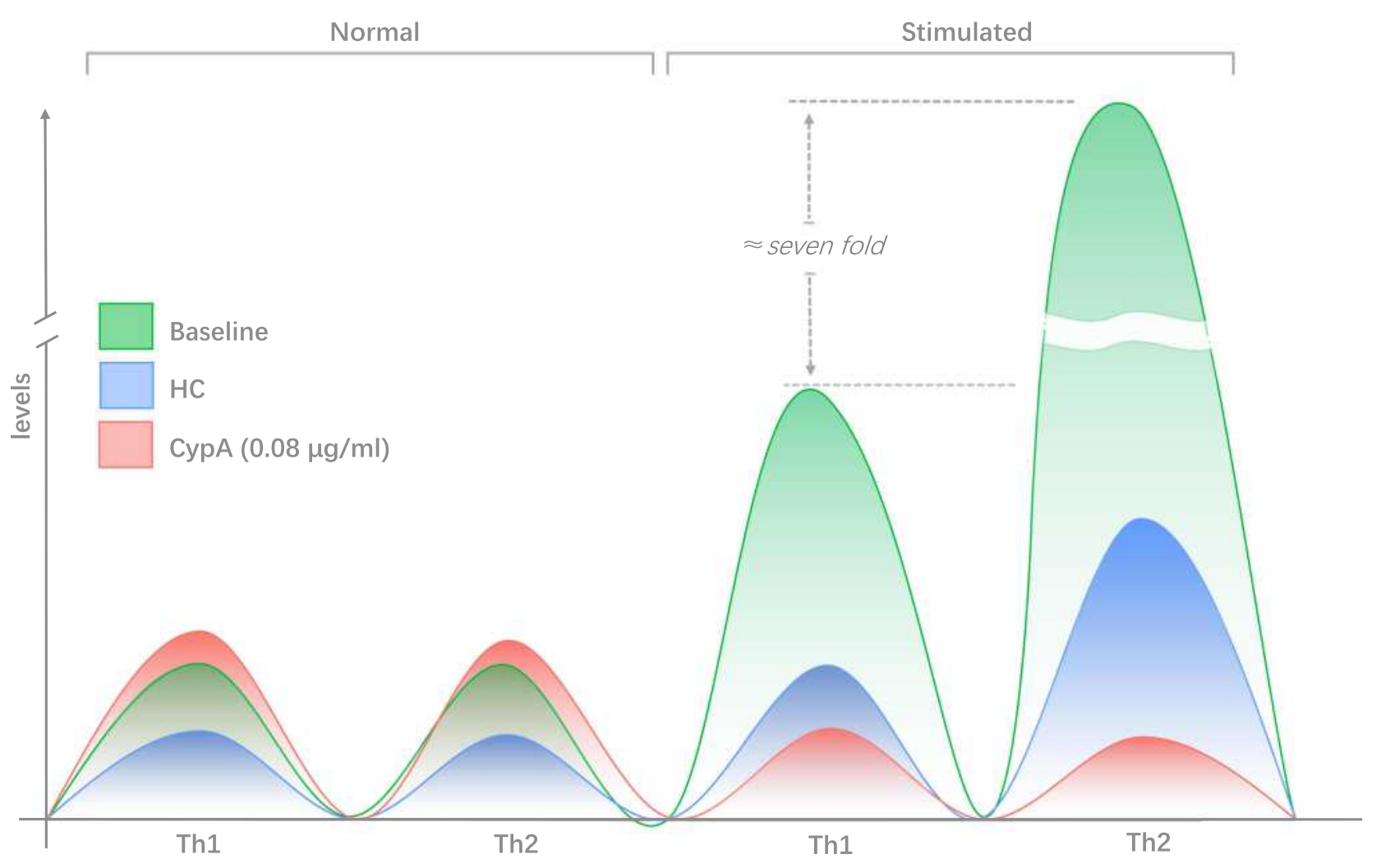

Figure 5 Schematic illustration of the suppressive effect of CypA on the levels of cytokines in the Non-stim and PWM-stim groups. The Y-axis represents an arbitrary measure of cytokines.

Otherwise, the data for rCypA on RL in this study showed that the effect of rCypA in reducing RL was almost the same as that of the positive drugs TB and HC. Further analyses of the effect of rCypA on tracheal spirals showed that rCypA significantly inhibited the ACh-induced isometric tension of tracheal spirals, and the effect was better than TB and quite comparable to that of HC. Airway smooth muscles (ASMs) are the main components of the tracheal spiral, and are considered critical effectors of bronchoconstriction and contraction. TB is a kind of $\beta_{2}$-receptor agonist conventionally used as the key drug for bronchoconstriction and contraction. ${ }^{40}$ In this study, TB reduced the isometric tension of the tracheal spiral from the beginning to $4 \mathrm{~min}$, while after that the contraction arose again. A previous study described a rebound increase in $\beta$ agonists during airway reactivity. ${ }^{41}$ The changes we observed for TB are likely to be due to desensitization of $\beta$-receptors on ASMs. ${ }^{42}$ Additionally, it should be mentioned here that, in addition to the immunotherapeutic effect of $\mathrm{HC}$ on asthma, $\mathrm{HC}$ can also promptly relax ASMs. ${ }^{43} \mathrm{HC}$ reduces bronchoconstriction by increasing the cyclic adenosine monophosphate level to reduce $\mathrm{Ca}^{2+}$ entry into ASMs. ${ }^{44}$
Additionally, recent studies indicated that overexpression of CypA can protect liver cells against oxidative damage. ${ }^{45}$ Meanwhile, this protective effect of CypA was also found in cardiomyocytes. ${ }^{46}$ Oxidative stress is believed to contribute to asthma pathogenesis, and a previous study reported that antioxidant therapy can be useful for asthma. ${ }^{47}$ Therefore, the mechanisms of CypA on oxidative stress involved in asthma should be noted. Thus far, our understanding of the mechanisms of CypA is far from complete. The role of CypA in the functioning of asthma with regard to the mechanism of reducing the RL and the isometric tension of tracheal spiral is unknown and is the subject of further study.

\section{Conclusion}

In summary, this work has demonstrated the effects of rCypA in asthma in both OVA-challenged asthmatic rats in vivo and ACh-induced contraction tracheal spirals ex vivo. The study also identified the underlying mechanism by which rCypA may have a precise role in limiting inflammation in asthma by suppressing the secretion of Th2 cytokines and balancing the ratio of Th1/Th2 
cytokines, indicating that CypA may serve as a potential novel therapeutic strategy for asthma.

\section{Abbreviations}

ACh, acetylcholine chloride; AS, asthmatic rats; ASMs, airway smooth muscles; BSA, bovine serum albumin; CsA, cyclosporin A; CypA, Cyclophilin A; eCypA, extracellular CypA; HC, hydrocortisone; ICS, inhaled corticosteroids; iCypA, intracellularly CypA; IFN- $\gamma$, interferon- $\gamma$; Ig, immunoglobulin; IL, interleukin; IPTG, isopropyl-beta -D-thiogalactopyranoside; Itk, interleukin-2 tyrosine kinase; LABA, long-acting $\beta_{2}$ agonist; Non-stim, Nonstimulated; NS, normal saline; OVA, ovalbumin; PPIase, peptidyl prolyl isomerase; PWM, pokeweed mitogen; PWM-stim, PWM-stimulated; rCypA, recombinant CypA protein; RL, pulmonary resistance; SD rats, Sprague Dawley rats; SPF, specific-pathogen free; TB, terbutaline; Th, T helper; TNF- $\alpha$, tumour necrosis factor alpha.

\section{Ethics Approval and Consent to Participate}

The animal procedures were reviewed and approved by the Committee on the Ethics of Animal Experiments of Shanghai University of Traditional Chinese Medicine and handled according to the recommendations of the National Institutes of Health Guide for Care and Use of the Laboratory Animals (Publication No. 8023, revised 1978). Ethical application number: PZSHUTCM190308020.

\section{Acknowledgments}

This study was supported by the National Natural Science Foundation of China (No. 81973951), Shanghai Sailing Program (No. 20YF1445300), National Key R\&D Program of China (No. 2018YFC1704600), Scientific Research Project of Shanghai Municipal Health Commission (No. 20194Y0164), National Natural Science Foundation of China (No. 81774429).

\section{Author Contributions}

All authors made substantial contributions to conception and design, acquisition of data, or analysis and interpretation of data; took part in drafting the article or revising it critically for important intellectual content; agreed to submit to the current journal; gave final approval of the version to be published; and agree to be accountable for all aspects of the work.

\section{Disclosure}

The authors declare that they have no conflicts of interest.

\section{References}

1. Global Initiative for Asthma(2020). Global strategy for asthma management and prevention; 2020. Available from: www.ginasthma.org. Accessed April 8, 2021.

2. Soriano JB, Abajobir AA, Abate KH, et al. Global, regional, and national deaths, prevalence, disability-adjusted life years, and years lived with disability for chronic obstructive pulmonary disease and asthma, 1990-2015: a systematic analysis for the Global Burden of Disease Study 2015. Lancet Respir Med. 2017;5(9):691-706. doi:10.1016/S2213-2600(17)30293-X

3. Fergeson JE, Patel SS, Lockey RF. Acute asthma, prognosis, and treatment. $J$ Allergy Clin Immunol. 2017;139(2):438-447. doi:10.1016/j.jaci.2016.06.054

4. McKeever T, Harrison TW, Hubbard R, Shaw D. Inhaled corticosteroids and the risk of pneumonia in people with asthma: a case-control study. Chest. 2013;144(6):1788-1794. doi:10.1378/chest.13-0871

5. Yim RP, Koumbourlis AC. Tolerance \& resistance to beta(2)-agonist bronchodilators. Paediatr Respir Rev. 2013;14(3):195-198. doi:10.1016/j.prrv.2012.11.002

6. Guan WJ, Zheng JP, Gao Y, et al. Responsiveness to leukotriene D4 and methacholine for predicting efficacy of montelukast in asthma. $J$ Thorac Dis. 2013;5(3):298-301. doi:10.3978/j.issn.20721439.2013.02.01

7. Yalcin AD, Bisgin A, Cetinkaya R, Yildirim M, Gorczynski RM. Clinical course and side effects of anti-IgE monoclonal antibody in patients with severe persistent asthma. Clin Lab. 2013;59(1-2):71-77. doi:10.7754/Clin.Lab.2012.120406

8. Gibson PG, Yang IA, Upham JW, et al. Effect of azithromycin on asthma exacerbations and quality of life in adults with persistent uncontrolled asthma (AMAZES): a randomised, double-blind, placebo-controlled trial. Lancet. 2017;390(10095):659-668. doi:10.1016/S0140-6736(17)31281-3

9. Caminati M, Pham DL, Bagnasco D, Canonica GW. Type 2 immunity in asthma. World Allergy Organ. 2018;11(1):13. doi:10.1186/ s40413-018-0192-5

10. Olin JT, Wechsler ME. Asthma: pathogenesis and novel drugs for treatment. BMJ. 2014;349(nov24 8):g5517. doi:10.1136/bmj.g5517

11. Tokunaga A, Sugiyama D, Maeda Y, et al. Selective inhibition of low-affinity memory CD8(+) T cells by corticosteroids. J Exp Med. 2019;216(12):2701-2713. doi:10.1084/jem.20190738

12. Williams DM. Clinical pharmacology of corticosteroids. Respir Care. 2018;63(6):655-670. doi:10.4187/respcare.06314

13. Kay AB. Immunosuppressive agents in chronic severe asthma. Allergy Proc. 1994;15(3):147-150. doi:10.2500/ 108854194778702838

14. Sihra BS, Kon OM, Durham SR, et al. Effect of cyclosporin A on the allergen-induced late asthmatic reaction. Thorax. 1997;52 (5):447-452. doi:10.1136/thx.52.5.447

15. Alexander AG, Barnes NC, Kay AB. Trial of cyclosporin in corticosteroid-dependent chronic severe asthma. Lancet. 1992;339 (8789):324-328. doi:10.1016/0140-6736(92)91646-P

16. Evans DJ, Cullinan P, Geddes DM. Cyclosporin as an oral corticosteroid sparing agent in stable asthma. Cochrane Database Syst Rev. 2000;5:CD002993. doi:10.1002/14651858.CD002993

17. Survase SA, Kagliwal LD, Annapure US, Singhal RS. Cyclosporin A-a review on fermentative production, downstream processing and pharmacological applications. Biotechnol Adv. 2011;29(4):418-435. doi:10.1016/j.biotechadv.2011.03.004

18. Colgan J, Asmal M, Yu B, Luban J. Cyclophilin A-deficient mice are resistant to immunosuppression by cyclosporine. J Immunol. 2005;174(10):6030-6038. doi:10.4049/jimmunol.174.10.6030 
19. Handschumacher RE, Harding MW, Rice J, Drugge RJ, Speicher DW. Cyclophilin: a specific cytosolic binding protein for cyclosporin A. Science. 1984;226(4674):544-547. doi:10.1126/ science. 6238408

20. Seko Y, Fujimura T, Taka H, et al. Hypoxia followed by reoxygenation induces secretion of cyclophilin A from cultured rat cardiac myocytes. Biochem Biophys Res Commun. 2004;317(1):162-168. doi:10.1016/j.bbrc.2004.03.021

21. Sherry B, Yarlett N, Strupp A, Cerami A. Identification of cyclophilin as a proinflammatory secretory product of lipopolysaccharide-activated macrophages. Proc Natl Acad Sci U S A. 1992;89(8):3511-3515. doi:10.1073/pnas.89.8.3511

22. Jin ZG, Melaragno MG, Liao DF, et al. Cyclophilin A is a secreted growth factor induced by oxidative stress. Circ Res. 2000;87 (9):789-796. doi:10.1161/01.RES.87.9.789

23. Brazin KN, Mallis RJ, Fulton DB, Andreotti AH. Regulation of the tyrosine kinase Itk by the peptidyl-prolyl isomerase cyclophilin A. Proc Natl Acad Sci U S A. 2002;99(4):1899-1904. doi:10.1073/ pnas.042529199

24. Schwartzberg PL, Finkelstein LD, Readinger JA. TEC-family kinases: regulators of T-helper-cell differentiation. Nat Rev Immunol. 2005;5(4):284-295. doi:10.1038/nri1591

25. Colgan J, Asmal M, Neagu M, et al. Cyclophilin A regulates TCR signal strength in $\mathrm{CD} 4+\mathrm{T}$ cells via a proline-directed conformational switch in Itk. Immunity. 2004;21(2):189-201. doi:10.1016/j. immuni.2004.07.005

26. Li J, Chen J, Zhang L, et al. One novel quinoxaline derivative as a potent human cyclophilin A inhibitor shows highly inhibitory activity against mouse spleen cell proliferation. Bioorg Med Chem. 2006;14(16):5527-5534. doi:10.1016/j.bmc.2006.04.026

27. Kofron JL, Kuzmic P, Kishore V, Colon-Bonilla E, Rich DH. Determination of kinetic constants for peptidyl prolyl cis-trans isomerases by an improved spectrophotometric assay. Biochemistry. 1991;30(25):6127-6134. doi:10.1021/bi00239a007

28. Yin LM, Li HY, Zhang QH, et al. Effects of S100A9 in a rat model of asthma and in isolated tracheal spirals. Biochem Biophys Res Commun. 2010;398(3):547-552. doi:10.1016/j.bbrc.2010.06.116

29. Xu Y-D, Wang Y, Yin L-M, et al. S100A8 protein attenuates airway hyperresponsiveness by suppressing the contraction of airway smooth muscle. Biochem Biophys Res Commun. 2017;484(1):184-188. doi:10.1016/j.bbrc.2017.01.033

30. Kim S-H, Lessner SM, Sakurai Y, Galis ZS. Cyclophilin A as a novel biphasic mediator of endothelial activation and dysfunction. $\mathrm{Am}$ $J$ Pathol. 2004;164(5):1567-1574. doi:10.1016/S0002-9440(10) 63715-7

31. Sun L, Yu G, Yang S, Zhang L. Effects of hydrocortisone on the differentiation of human T helper 2 cells. Scand J Immunol. 2011;73 (3):208-214. doi:10.1111/j.1365-3083.2010.02500.x

32. Packard KA, Khan MM. Effects of histamine on Th1/Th2 cytokine balance. Int Immunopharmacol. 2003;3(7):909-920. doi:10.1016/ S1567-5769(02)00235-7
33. Watanabe N, Kobayashi A. Nippostrongylus brasiliensis: radioresistant IgE antibody-forming cells in infected rats. Exp Parasitol. 1989;68(2):216-222. doi:10.1016/0014-4894(89)90100-8

34. Barnig C, Frossard N, Levy BD. Towards targeting resolution pathways of airway inflammation in asthma. Pharmacol Ther. 2018;186:98-113. doi:10.1016/j.pharmthera.2018.01.004

35. PubChem Compound Summary for CID 5754, Hydrocortisone. National library of medicine (US), national center for biotechnology information; 2021. Available from: https://pubchem.ncbi.nlm.nih. gov/compound/Hydrocortisone. Accessed April 8, 2021.

36. Katial RK, Sachanandani D, Pinney C, Lieberman MM. Cytokine production in cell culture by peripheral blood mononuclear cells from immunocompetent hosts. Clin Diagn Lab Immunol. 1998;5(1):78-81. doi:10.1128/CDLI.5.1.78-81.1998

37. Stemmy EJ, Balsley MA, Jurjus RA, et al. Blocking cyclophilins in the chronic phase of asthma reduces the persistence of leukocytes and disease reactivation. Am J Respir Cell Mol Biol. 2011;45(5):991-998. doi:10.1165/rcmb.2011-0007OC

38. Stemmy EJ, Benton AS, Lerner J, et al. Extracellular cyclophilin levels associate with parameters of asthma in phenotypic clusters. J Asthma. 2011;48(10):986-993. doi:10.3109/02770903.2011.623334

39. Benton AS, Wang Z, Lerner J, et al. Overcoming heterogeneity in pediatric asthma: tobacco smoke and asthma characteristics within phenotypic clusters in an African American cohort. J Asthma. 2010;47(7):728-734. doi:10.3109/02770903.2010.491142

40. Hershenson MB, Brown M, Camoretti-Mercado B, Solway J. Airway smooth muscle in asthma. Annu Rev Pathol. 2008;3(1):523-555. doi:10.1146/annurev.pathmechdis.1.110304.100213

41. Vathenen AS, Knox AJ, Higgins BG, Britton JR, Tattersfield AE. Rebound increase in bronchial responsiveness after treatment with inhaled terbutaline. Lancet. 1988;1(8585):554-558. doi:10.1016/ S0140-6736(88)91352-9

42. Barnes PJ. Neural control of human airways in health and disease. Am Rev Respir Dis. 1986;134(6):1289-1314. doi:10.1164/ arrd.1986.134.5.1289

43. Lefcoe NM. The effect of hydrocortisone hemisuccinate on tracheal smooth muscle of the guinea pig and cat. $J$ Allergy. 1956;27 (4):352-358. doi:10.1016/0021-8707(56)90074-0

44. Andersson RG, Kovesi G. The effect of hydrocortisone on tension and cyclic AMP metabolism in tracheal smooth muscle. Experientia. 1974;30(7):784-786. doi:10.1007/BF01924186

45. Kim K, Oh IK, Yoon KS, et al. Antioxidant activity is required for the protective effects of cyclophilin A against oxidative stress. Mol Med Rep. 2015;12(1):712-718. doi:10.3892/mmr.2015.3392

46. Cheng F, Yuan W, Cao M, et al. Cyclophilin A protects cardiomyocytes against hypoxia/reoxygenation-induced apoptosis via the AKT/ Nox2 pathway. Oxid Med Cell Longev. 2019;2019:2717986. doi: $10.1155 / 2019 / 2717986$

47. Fujisawa T. Role of oxygen radicals on bronchial asthma. Curr Drug Targets Inflamm Allergy. 2005;4(4):505-509. doi:10.2174/ 1568010054526304

\section{Publish your work in this journal}

The Journal of Asthma and Allergy is an international, peer-reviewed open-access journal publishing original research, reports, editorials and commentaries on the following topics: Asthma; Pulmonary physiology; Asthma related clinical health; Clinical immunology and the immunological basis of disease; Pharmacological interventions and new therapies. The manuscript management system is completely online and includes a very quick and fair peer-review system, which is all easy to use. Visit http://www.dovepress.com/testimonials.php to read real quotes from published authors. 